\title{
REVIEW
}

\section{The guarding reflex revisited}

\author{
J.M. PARK, D.A. BLOOM and E.J. McGUIRE*
}

Section of Urology, Department of Surgery, University of Michigan Medical School, Ann Arbor, Michigan, and *Department of

Urology, University of Texas Medical School Houston, Texas, USA

\section{Introduction}

Normal lower urinary tract function after toilet training (low-pressure storage and periodic volitional emptying) results from close co-ordination between central and peripheral neural circuits. Although other visceral organs depend upon neural modulation for optimal regulation of their functions, the lower urinary tract is unique in that its dependence upon nervous system control appears to be absolute. Without neural input, the lower urinary tract can no longer function adequately, as shown by the many well-documented voiding dysfunctions associated with various neurological disorders. In contrast, other organ systems (such as cardiovascular and gastrointestinal) are able to maintain a high degree of function even after central nervous system input is eliminated. Despite most of the neural circuits involved in controlling lower urinary tract function being autonomic, micturition and storage are under precise volitional control. Again, such is not the case with other organs regulated by the autonomic nervous system. Humans cannot voluntarily adjust the rate of gastric emptying or turn off blood-pressure regulation. How is such control of the bladder possible? Is there a physiological 'on-off' switch for bladder activity? In this review, we revisit the concept of the 'guarding reflex', examine several voiding disorders in terms of guarding reflex dysfunction, and propose a hypothesis that the volitional bladder control mechanism resides at the external urethral sphincter. While some of the proposals outlined in this review represents the opinion of the authors, the intent is to stimulate further thought and investigation. As Abernathy stated in 1809 [1]:

'Various advantages result even from the publication of opinions; for though we are very liable to error in formulating them, yet their promulgation, by exciting investigation, and pointing out the deficiencies of our information, cannot be otherwise than useful in the promotion of science.'

Accepted for publication 19 August 1997

\section{The origin of the term 'guarding reflex'}

The concept of a reflex as an involuntary motor response to a specific stimulus, involving a spinal pathway, has been known since it was beautifully illustrated in 1664 for Rene Descartes', Treatise of Man [2] (Fig. 1). Neural reflex pathways involved in the modulation of lower urinary tract function have been sought throughout this century. In 1915, Barrington proposed a series of neural reflexes, based upon careful observations of selectively denervated laboratory animals, to explain the events of micturition [3]. Barrington's concept of micturition reflexes originated from studies of pressure and volume variation in the bladder and urethra. With the introduction of EMG, it became possible to examine the events surrounding micturition kinesiologically [4], i.e. an activity of one muscle group (e.g. bladder) could be studied in relation to that of another (e.g. sphincter). It

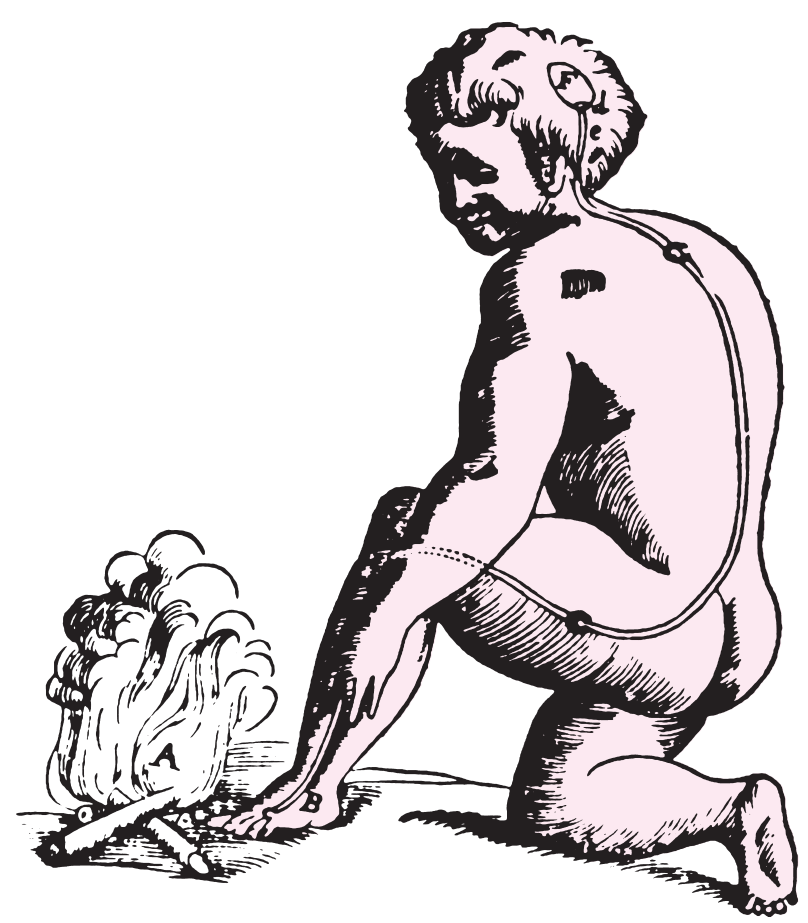

Fig. 1. Depiction of 'Reflex' in Descartes' Treatise of Man, 1664. 
soon became evident that not only micturition but also continence and storage were controlled by a distinct set of neural reflexes. The term guarding reflex was first used by R.C. Garry, a physiologist from the University of Glasgow, in his 1959 manuscript [5]:

'Barrington, in his preoccupation with reflexes promoting emptying of the bladder, perhaps gave too little consideration to guarding reflexes which prevent emptying of the bladder. ... As the bladder fills, the muscular bladder wall adapts itself to the increasing volume with little increase in intravesical pressure. ... As filling continues, the continence is assured by increased activity in the external urethral sphincter. Should urine enter the urethra at this stage, the activity of the external sphincter is still further increased - the guarding reflexes.'

Garry et al. [5] proposed that such reflex increase in the activity of the external urethral sphincter may be the primary mechanism to mitigate against unwanted stress incontinence.

\section{The current view of the guarding reflex}

Since this description, the term guarding reflex has become established in the contemporary vocabulary of urodynamics. In most current textbooks, the guarding reflex refers to a progressive, involuntary increase in the activity of the external urethral sphincter during bladder filling, and this is measured by either an intraluminal pressure transducer placed at the highest pressure zone of urethral profilometry or by perineal EMG [4,6-7]. This variation in the external urethral sphincter activity does not occur randomly, but rather is closely related to the state of bladder activity. The external urethral sphincter activity reaches a peak just before the onset of micturition. The voiding contraction is characteristically preceded by a complete relaxation (i.e. electrical silence on EMG) of the external urethral sphincter. Indeed, this relaxation of the external sphincter may be the first measurable event of micturition. When presented with a request to stop voiding before complete emptying of the bladder, an individual halts micturition by first contracting the external urethral sphincter, temporarily raising the intravesical pressure, after which bladder contraction ceases abruptly (Fig. 2). At low bladder volume, the guarding reflex is present without sensory awareness by the person whose bladder is being filled. In other words, the reflex appears to be involuntary. When the sensory threshold of bladder fullness is reached, the external urethral sphincter activity increases even further as the person actively tries to remain dry in juxtaposition to a full bladder wanting to empty, thus becoming a conscious and voluntary phenomenon. The lower urinary tract sensory purview has a range that is variable in terms of age, time and

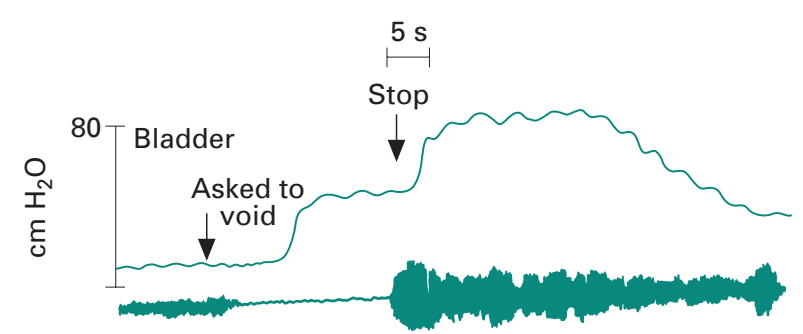

Fig. 2. Stop-flow test in a neurologically normal individual. The top tracing represents the CMG and the bottom the EMG activity of the external urethral sphincter. Note that the bladder contraction is preceded by electrical silence from the external urethral sphincter, and with the return of external sphincter activity, bladder contraction subsides.

social stress. This is seen in clinical conditions such as infrequent voiding at the one extreme and extraordinary frequency at the other $[8,9]$. Several stimuli can elicit an increase in the external urethral sphincter activity, such as cough, Crede and Valsalva manoeuvres, and the bulbocavernosal reflex [4]. It is as if the body senses the potential for urine leakage in these situations of stress and relies upon the augmented guarding reflex to prevent unwanted urine loss.

\section{The neurological basis for the guarding reflex}

Most models of lower urinary tract function support the notion that the external urethral sphincter is innervated by both somatic (pudendal) and autonomic (sympathetic) nerves, whereas the bladder is innervated by autonomic nerves only, i.e. sympathetic and parasympathetic [10]. Parasympathetic motor nerves (S2-4) induce a contractile response of the bladder, whereas sympathetic (T12-L2) nerves inhibit it. As the bladder distends with increasing urine volume, stretch-sensitive mechanoreceptors in the bladder wall generate afferent signals to the spinal cord and subsequently to the supraspinal micturition centres. If continence and storage are to be maintained, the integrated supraspinal input generates a response to sacral and thoracolumbar spinal-cord segments that in turn elicit and maintain bladder inhibition. The synthesis of guarding reflex appears to require the participation of the pontine micturition centre. Siroky and Krane, in their study of patients with spinal cord injury, found that the guarding reflex was absent in over $85 \%$ of patients with complete cord injuries, but it was nearly always present in patients with either incomplete injuries or suprapontine lesions [11]. The essential components of the bladder inhibitory mechanism via external urethral sphincter activation appear to reside at the sacral spinal cord level. In non-human primates, stimulation of the external urethral sphincter results in a profound inhibition of the bladder even after 
suprasacral spinal cord transection [12]. With guarding reflex activation, the afferent signals probably travel from the contracting external urethral sphincter via pudendal branches to the sacral cord, and inhibit parasympathetic bladder motor neurons directly through spinal interneurons. Further inhibition may occur by increasing thoracolumbar sympathetic influence upon the bladder. Increased sympathetic activity inhibits the bladder's contractile response by directly inhibiting the bladder smooth muscle cells through beta-receptors or by interference of ganglionic transmission of parasympathetic bladder motor neurons. Teleologically, the bladder wants to be emptied of its contents, even more so as it becomes full, and it takes an increasing amount of neural network to keep it from doing it so.

\section{Clinical implications of guarding reflex dysfunction}

\section{Idiopathic detrusor instability}

Incontinence secondary to uninhibited bladder contractions in neurologically normal individuals is called idiopathic detrusor instability. The definition of this voiding dysfunction by the ICS was initially based on urodynamic findings, i.e. a rise in intravesical pressure of $>15 \mathrm{cmH}_{2} \mathrm{O}$ during a provocative filling cystometrogram (CMG). It was later recognized that a pressure increase alone was not necessarily the result of reflex bladder contraction, and the definition was changed to include detrusor phasic activity of any magnitude [13]. In clinical practice, a routine CMG often fails to elicit aberrant bladder contractions in these patients, despite a history characteristic of incontinence from detrusor instability. Yet continuous ambulatory monitoring of bladder pressures suggests that most patients who complain of urge incontinence have sudden uncontrolled bladder contractions with no sensory warnings. A possible explanation for this discrepancy may be found in the guarding reflex.

Multichannel urodynamic study in these patients, examining simultaneously the external urethral sphincter and bladder activity, often reveals an abnormal guarding reflex as the sole finding (Fig. 3). Instead of a gradual, sustained increase in the external sphincter activity during filling, an intermittent loss of activity is noted instead and this phenomenon, termed urethral instability, can be seen with no change in sensory appreciation of bladder filling or contraction [14-16]. The ICS attempted to define urethral instability as urethral pressure variation of $>15 \mathrm{cmH}_{2} \mathrm{O}$ during bladder filling [16]. This definition, or the significance of the phenomenon, was not widely accepted. A few clinical trials tried to address patients refractory to traditional anti-cholinergic medication, by treating them with

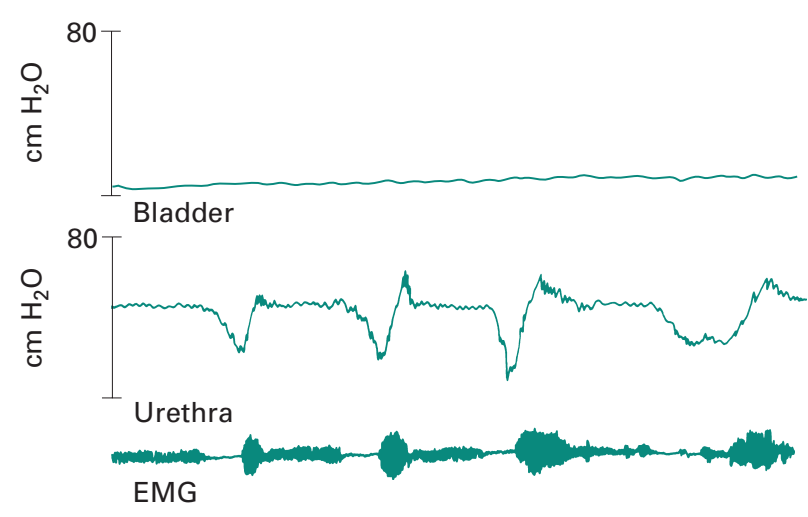

Fig. 3. Urodynamic tracing from a patient with detrusor instability. Even without the actual appearance of a bladder contraction on the CMG (top tracing), 'urethral instability' is evident during bladder filling, as manifested by sudden decreases in intraluminal pressure and EMG activity.

sympathomimetic agents likely to increase tonic urethral coaptation, based on this rationale [14]. Perhaps in these individuals the initial and primary abnormality leading to the uncontrolled bladder contractions might be premature loss of the guarding reflex by the external urethral sphincter. However, because the guarding reflex can be voluntarily augmented, patients intensely focused upon events in the lower urinary tract events may artefactually suppress bladder activity in testing situations by consciously contracting the external urethral sphincter, resulting in false-negative findings. The presence of a urethral catheter may also increase wall tension at the external urethral sphincter, further augmenting the guarding reflex. The cause of urethral instability is unknown. Inherent instability may exist in the pudendal nucleus of the sacral spinal cord [17].

Defects may be more peripheral due to structural loss (i.e. tissue atrophy, peripheral denervation) of the external urethral sphincter itself. Post-menopausal detrusor instability, often helped by local oestrogen therapy, may be caused by peri-urethral tissue atrophy. The maintenance of tissue integrity requires a delicate balance amongst various local and systemic factors, such as growth factors, neural input, mechanical stress, and hormonal milieu.

\section{Detrusor external urethral sphincter dyssynergia}

Patients with suprasacral spinal cord injury may have dyssynergia between detrusor and the external urethral sphincter, wherein involuntary, phasic detrusor contractions are coupled with opposing contractions by the external sphincter, resulting in elevated intravesical pressures, high residual urine volumes and incontinence (Fig. 4). With the loss of descending suprasacral input 

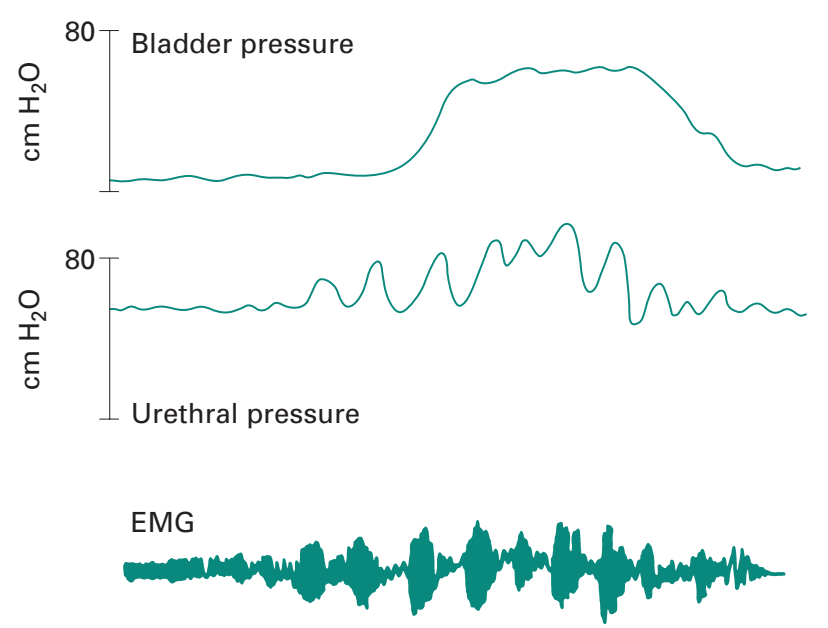

Fig. 4. Detrusor external urethral sphincter dyssynergia in a quadriplegic patient. Note the sequential 'contraction-relaxation' by the external urethral sphincter in the face of the contracting detrusor.

from the micturition centre, there is a premature decrease, rather than a stable increase, in the external urethral sphincter activity during bladder filling. When external sphincter activity becomes low enough, coupled with critical fullness of the bladder, voiding contractions are initiated, much as occurs with normal voluntary voiding. With the onset of the bladder contraction, a strong counter-contraction of the external urethral sphincter then follows, as if the body attempts to belatedly control the unwanted urine loss. Garry described this activation of the guarding reflex ('should urine enter the urethra'), whether fluid was introduced in an antegrade or retrograde fashion [5]. Sudden flow of urine into the urethra near the external urethral sphincter probably causes acute activation of local stretch receptors, leading to pudendal nerve-mediated bladder inhibition. Bladder contraction is initially suppressed, but the external urethral sphincter activity is poorly sustained because there is no supraspinal input, failing to suppress completely the bladder. The above dyssynergic patterns repeat cyclically. Thus, detrusor sphincter dyssynergia in patients with spinal cord injury may be a manifestation of the improper execution and coordination of the guarding reflex by the external urethral sphincter, resulting from a loss of input from the supraspinal micturition centre [18].

\section{Non-neuropathic neuropathic bladder syndrome}

In 1915, Beer described a condition in children of 'disharmony between detrusor and sphincter muscles' [19]. This has come to be known as non-neuropathic neuropathic bladder syndrome, or Hinman syndrome, with clinical manifestations ranging from urinary tract infections and incontinence to functional damage of the entire urinary tract [20]. The description of this as a neuropathic condition rather than a neurogenic one emphasizes the conventional wisdom that this is an acquired rather than congenital disorder. Here, an obstructive pathophysiology appears to be secondary to functional rather than anatomical causes. As we noted previously, the guarding reflex can be augmented voluntarily by forceful contraction of the pelvic floor muscles in an attempt to hold back a full bladder.

In the Hinman syndrome, the patients probably develop a dis-coordinate relationship between the bladder and external urethral sphincter by chronic volitional augmentation of the guarding reflex, in opposition to full bladders that want to empty [21].

\section{Nocturnal enuresis}

There may be several mechanisms of nocturnal enuresis, but the natural history of this voiding dysfunction clearly seems to reflect a dependence upon neural maturation. The guarding reflex may also be important in bedwetting. Human sleep has two distinct stages, rapid-eye movement (REM) and non-REM sleep; during the latter there is a progressive differential relaxation of most somatic muscles and predominance of parasympathetic discharge, characterized by declines in heart rate, blood pressure and respiratory rate, with an accompanying increase in gastrointestinal motility. In comparison, REM sleep is accompanied by increased sympathetic output, resulting in an opposite phenomenon, with active inhibition of somatic muscle tone [22]. Perhaps in some nocturnal enuretics the activity of the external urethral sphincter prematurely falls below a critical threshold during these sleep-cycle transitions and thereby triggers a bladder contraction. These factors may operate in older nocturnal enuretics who are not responsive to the typical pharmacological and behavioural interventions. Many patients with nocturnal enuresis have urodynamic findings similar to those with idiopathic detrusor instability [21]. Indeed, most urodynamic studies performed during sleep have shown patterns of uninhibited bladder contractions, as well as urethral instability, as described previously [23-25].

\section{Post-prostatectomy incontinence}

Urinary incontinence is still a feared complication after radical prostatectomy. Even in patients who eventually achieve reasonable continence, recovery can take months. There is no consensus about the prevention of incontinence after prostatectomy, other than to preserve an ample urethral remnant. The pattern of incontinence in the early post-operative period after radical 
prostatectomy is not well characterized. Incontinence patterns discerned by careful questioning suggest that both stress and urge incontinence may operate. A few recent reports suggested that de novo detrusor instability after radical prostatectomy may be a significant factor $[26,27]$. The key to this voiding dysfunction could also lie in the external urethral sphincter guarding reflex. The stress of surgical manipulation near the prostatic apex, resulting in structural loss of the external urethral sphincter motor units or local neural injury, would weaken the guarding reflex, thus encouraging bladder instability. Most urologists have observed that minimal dissection and handling of the external urethral sphincter region during the apical dissection of prostate leads to a better and faster eventual recovery of continence $[28,29]$. This notion has led to the confusion about the role of the external urethral sphincter in stress incontinence, when its contribution may have been the preservation of the integrity of the guarding reflex.

\section{Therapeutic options affecting the guarding reflex}

In many clinical situations there is evidence of bladder modulation by the external urethral sphincter. For example, urethral dilation was traditionally performed in female patients suffering from intractable urgency and incontinence, with the rational that urethral stenosis was being relieved. Urodynamic studies have disproved the concept of urethral stenosis. However, anecdotal testaments of women who had dramatic relief from symptoms of infection and incontinence after urethral dilation remain disconcerting. In retrospect, the therapeutic efficacy of urethral dilation in some instances may have been due to modulation of the guarding reflex. Acute stretching of the external urethral sphincter may have promoted the proliferation of local tissue or re-organization of neural reflexes, resulting in a more sustained guarding reflex. Mechanical stretch is a powerful regulator of tissue proliferation and remodelling. In patients with a neurogenic bladder, e.g. from spina bifida, urethral dilation was initially applied at our institution to decrease the leak-point pressure by mechanically lowering the outlet resistance at the external urethral sphincter level, but it was later shown to improve bladder compliance and reduce uninhibited bladder contractions [30,31]. Pelvic floor muscle exercises (Kegel) may affect continence by neuromuscular reinforcement of the guarding reflex, not simply by increasing the mechanical muscle bulk to the outlet [32]. Electrical stimulation (transvaginal, perineal, pudendal nerve, and penile nerve) is moderately effective in the treatment of incontinence, and often the therapeutic results are best seen in patients with uninhibited bladder contractions, e.g. those with detrusor instability and spinal cord injury $[33,34]$. This effect may also arise from neuromuscular stimulation of the external urethral sphincter, similar to the guarding reflex.

\section{The guarding reflex; the bladder's 'on-off' switch?}

The bladder appears to have an inherent tendency to empty itself during filling and it is necessary that tendency is harnessed by inhibitory neural circuits to maintain low-pressure storage and continence. Furthermore, a connection must exist between voluntary somatic neuromuscular control and involuntary autonomic regulation. The key to bladder control may lie in the external urethral sphincter guarding reflex. In describing the task of the external urethral sphincter, the notion that it provides sufficient sphincteric closure to mitigate against stress incontinence, as perhaps Garry once thought, can be categorically dismissed. This seems to be more the mission of the smooth muscle in the proximal portion of urethra and bladder neck. On the other hand, co-ordinated relaxation of the external urethral sphincter is essential during normal micturition and the complete quiescence of these skeletal muscles always precedes detrusor contraction. Therefore, one logical hypothesis for the role of the external urethral sphincter in lower urinary tract function is its service as the 'on-off' switch for voiding. This beautiful piece of bioengineering seems to be a unique conscious link to an autonomous function, whereby relaxation of the external urethral sphincter (suppression of the guarding reflex) initiates micturition, whereas contraction (enhancement) suppresses bladder contractility.

\section{References}

1 Abernathy J. Surgical Observations. Preface, London: Longman, Hurst, Rees and Orme, 1809: iv

2 Shapin S. The Scientific Revolution. Chicago: University of Chicago Press, 1996: 49

3 Barrington FJF. The nervous mechanism of micturition. Quart J Exp Physiol 1915; 8: 33-71

4 Wein AJ. Neuromuscular dysfunction of the lower urinary tract. In Walsh PC, Retik AB, Stamey TA, Vaughan ED eds, Campbell's Urology, $6^{\text {th }}$ edn., vol 2, WB Saunders Co, 1992: 573-642

5 Garry RC, Roberts TDM, Todd JK. Reflexes involving the external urethral sphincter in the cat. J Physiol 1959; 149: 653-65

6 McGuire EJ. Physiology of the lower urinary tract. Am J Kid Dis 1983; 2: 402-8

7 Blaivas JG. The neurophysiology of micturition: a clinical study of 550 patients. J Urol 1982; 127: 958-63

8 Bloom DA, Seeley WW, Ritchey ML, McGuire EJ. Toilet habits and continence in children: an opportunity sampling in search of normal parameters. J Urol 1993; 149: 1087-90 
9 Zoubek J, Bloom DA, Sedman AB. Extraordinary urinary frequency. Pediatrics 1990; 85: 1112-4

10 De Groat WC. Anatomy and physiology of the lower urinary tract. Urol Clin N Am 1993; 20: 383-401

11 Siroky MB, Krane RJ. Neurologic aspects of detrusorsphincter dyssynergia, with reference to the guarding reflex. J Urol 1982; 127: 953-7

12 McGuire EJ, Morrissey S, Zhang S, Horwinski E. Control of reflex detrusor activity in normal and spinal cord injured non-human primates. J Urol 1983; 129: 197-9

13 McGuire EJ. Idiopathic bladder instability. In Kursh ED, McGuire EJ eds, Female Urology, 1st edn. Philadelphia: JB Lippincott Co, 1994

14 Wise BG, Cardozo LD, Cutner A, Benness CJ, Burton G. Prevalence and significance of urethral instability in women with detrusor instability. Br J Urol 1993; 72: 26-9

15 Vereecken RL, Cornelissen M, Das J, Grisar P. Urethral and perineal instability. Urol Int 1985; 40: 325-30

16 Vereecken RL, Das J. Urethral instability: related to stress and/or urge incontinence? J Urol 1985; 134: 698-701

17 Mahony DT, Laferte RO, Blais DJ. Incontinence of urine due to instability of micturition reflexes. Part II. Pudendal nucleus instability. Urology 1980; 15: 379-88

18 Rudy DC, Awad SA, Downie JW. External sphincter dyssynergia: an abnormal continence reflex. J Urol 1988; 140: $105-10$

19 Beer E. Chronic retention of urine in children. JAMA 1915; 65: 1709

20 Hinman F Jr. Non-neurogenic neurogenic bladder (the Hinman Syndrome) - 15 years later. J Urol 1986; 136: $769-77$

21 McGuire EJ, Savastano JA. Urodynamic studies in enuresis and the non-neurogenic neurogenic bladder. J Urol 1984; 132: 299-302

22 Pressman MR, Fry JM. What is normal sleep? Clin Ger Med 1988; 4: 71-81

23 Robert M, Averous M, Besset A et al. Sleep polygraphic studies using cystomanometry in twenty patients with enuresis. Eur Urol 1993; 24: 97-102

24 Norgaard JP, Hansen JH, Wildschiotz G, Sorensen S, Rittig S, Djurhuus JC. Sleep cystometries in children with nocturnal enuresis. J Urol 1989; 141: 1156-9
25 Penders L, de Leval J, Petit R. Enuresis and urethral instability. Eur Urol 1984; 10: 317-22

26 Goluboff ET, Chang DT, Olsson CA, Kaplan SA. Urodynamics and the etiology of post-prostatectomy urinary incontinence: the initial Columbia experience. J Urol 1995; 153: $1034-7$

27 Leach GE. Post-prostatectomy incontinence: the importance of bladder dysfunction. J Urol 1995; 153: 1034-7

28 Narayan P, Konety B, Aslam K, Aboseif S, Blumenfeld W, Tanagho E. Neuroanatomy of the external urethral sphincter: implications for urinary continence preservation during radical prostate surgery. J Urol 1995; 153: 337-41

29 Klein EA. Modified apical dissection for early continence after radical prostatectomy. Prostate 1993; 22: 217-23

30 Bloom DA, Knechtel JM, McGuire EJ. Urethral dilation improves bladder compliance in children with myelomeningocele and high leak point pressures. J Urol 1990; 144: 430-3

31 Park JM, Wedemeyer G, Bloom DA. Suppression of uninhibited bladder contractions in spinal cord injury patients by stimulation of external urethral sphincter. Abstract 83. American Academy of Pediatrics Annual Meeting, Section on Urology, San Francisco, CA, October 23, 1995

32 Schneider MS, King LR, Surwit RS. Kegel exercises and childhood incontinence: a new role for an old treatment. J Pediat 1994; 124: 91-2

33 Fall M. Does electrostimulation cure urinary incontinence? J Urol 1984; 131: 664-7

34 Wheeler JS Jr, Walter JS, Zaszczurynski PJ. Bladder inhibition by penile nerve stimulation in spinal cord injury patients. J Urol 1992; 147: 100-3

\section{Authors}

J.M. Park, MD, Lecturer in Urology.

D.A. Bloom, Professor, Chief of Pediatric Urology.

E.J. McGuire, Professor, Chief of Urology.

Correspondence: Dr D.A. Bloom, 1500 East Medical Center, Ann Arbor, MI 48109-0330, USA. 